\title{
DEVELOPMENT OF SAND BYPASS SYSTEM USING A SELF-SINKING SUCTION PIPE WITH HOLES FOR AUTOMATTON AND LABOR SAVING
}

\author{
Hitoshi Noguchi \\ Construction and Control Systems Department \\ Port and Airport Research Institute \\ 3-1-1 Nagase, Yokosuka, 239-0826, Japan \\ Emailnnoguchi@pari.go.jp
}

\author{
Yuji Fujita \\ Construction and Control Systems Department \\ Port and Airport Research Institute \\ 3-1-1 Nagase, Yokosuka, 239-0826, Japan \\ Email fujita-y@pari.go.jp
}

\begin{abstract}
Many coastal areas in Japan are in a distressed condition due to beach erosion. Sand bypass systems offer one countermeasure for beach erosion.

In the conventional sand bypass method, heavy equipment such as a backhoe is used to collect sand when the location is above sea level, and a dredging ship is used when the sand source is below sea level. Sand is collected by moving the sandcollecting device.

This means that some mechanism for movement of the sand-collecting device and mobile equipment such as a truck or ship are indispensable, and considerable manpower is necessary, including dump truck drivers and others.

This report proposes a new sand bypass system with a simple composition comprising a suction pipe with holes to automate and save labor. The effectiveness of the system was demonstrated in field experiments in seabed sand collection and beach sand collection
\end{abstract}

Keywords: self-sinking, suction pipe, sand-bypass, labor saving

\section{INTRODUCTION}

Many coastal areas in Japan are in a distressed condition due to beach erosion, making beach preservation and restoration important issues.

Methods of preventing beach erosion can be categorized as structural methods, which employ breakwaters and training walls to prevent sand drift caused by waves, and sand bypass methods, in which sand lost to beach erosion is periodically replenished.

In the conventional sand bypass method, heavy equipment such as a backhoe is used to collect sand when the location is above sea level, and a dredging ship is used when the sand source is below sea level (Fig-1,2).

Sand is collected from a wide area by moving the sand-collecting device (shovel or dredging head) while the sand essentially remains static.

This means that some mechanism for movement of the sand-collecting device and mobile equipment such as a truck or ship are indispensable, and personnel are necessary to operate this equipment.

In transportation, repeated movement by dump truck is inefficient, as a driver is required for each truck and trucks return to the sand collection site empty.

Trucking is also undesirable from the environmental viewpoint, as it causes air pollution and increases traffic congestion.

Thus, a method that makes it possible to recover sand using a simple sand collection system that requires no mechanism for movement and deliver the sand as collected to the placement site by pipeline can be expected to automate and save labor.

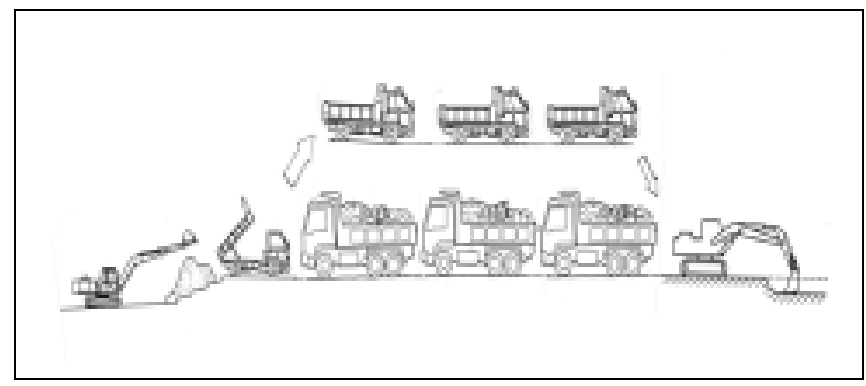

Fig-1 Backhoe loading and dump truck transportation

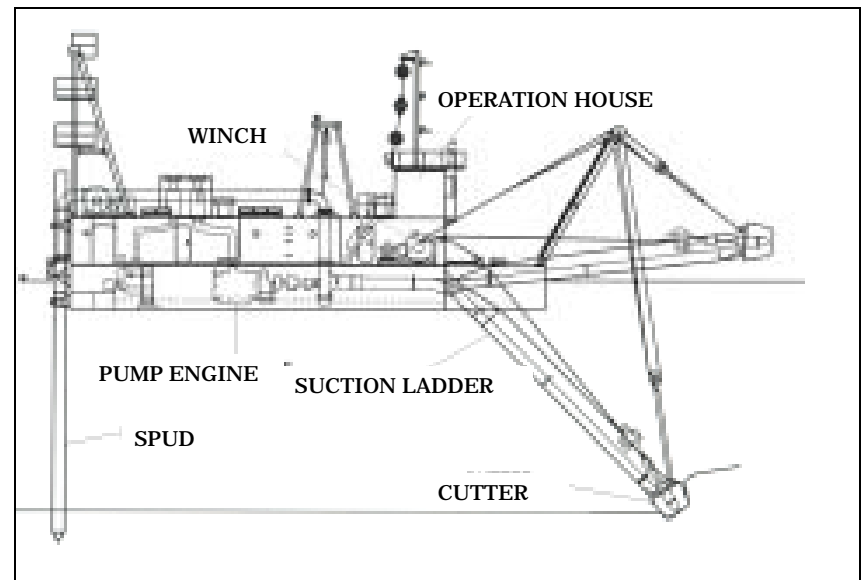

Fig-2 Pump Dredger

In this research, the authors developed a self-sinking sand bypass system using simple, compact equipment that can be operated continuously and requires a minimum of only one portable sand-collecting device. 


\section{OUTLINE OF SAND COLLECTION/TRANSPORTATION METHOD}

In the newly- developed sand bypass system, a sand collection site is established at a location where sand has accumulated. Because sand tends to accumulate at such sites due to topographic and marine climatic conditions, these natural forces are employed when possible to collect sand in the sand collection device. In principle, the sand collection device is stationary.

Thus, labor saving and automation can be expected if the collected sand can be drawn into the device with seawater and transported in the form of slurry, by a slurry pipeline.

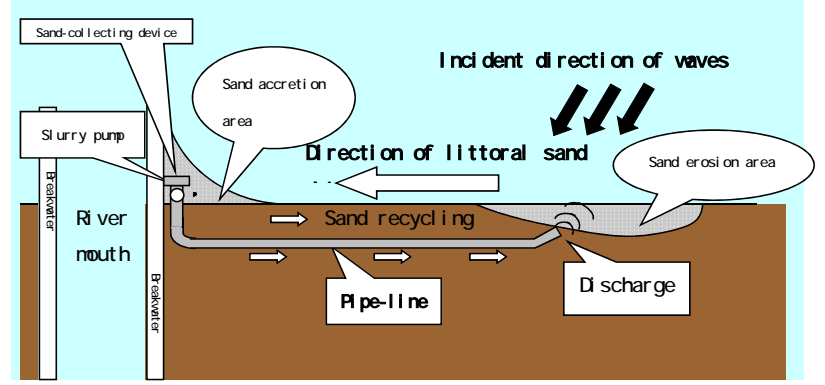

Fig-3 Outline of sand bypass system using self-sinking suction pipe

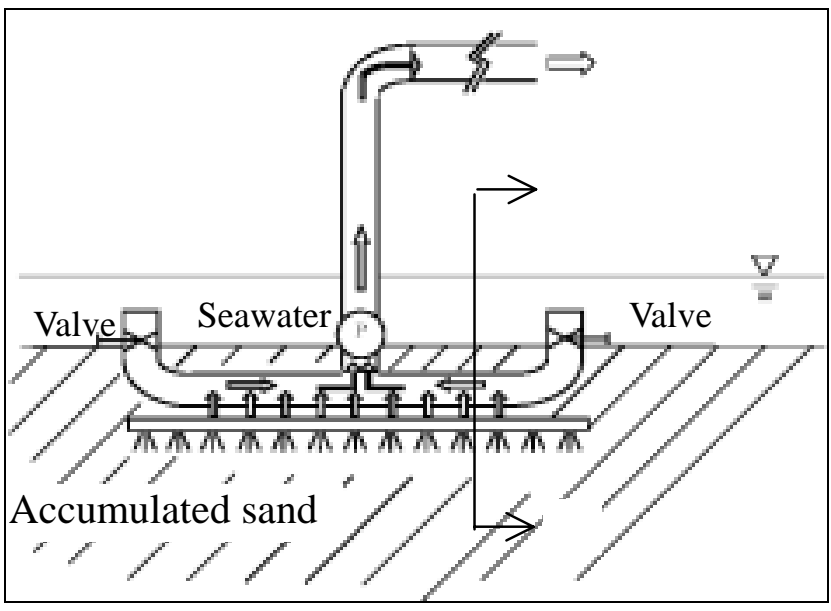

Fig- 4 Method (front sectional view)

A sand suction pipe with an appropriate number of holes (hereinafter called suction pipe) is used to collect sand from the trench (sand trap) which forms around the pipe.

Water jet outlets are installed under the suction pipe to fluidize the surrounding sand and sink the suction pipe system.

In the simplest form, the both ends of the suction pipe are below water, and can be used to supply seawater through a closable valve when necessary to dilute the slurry.

The center exit is connected to the slurry pump.

The water jets fluidize the surrounding sand, allowing the suction pipe system to sink into the sand under its own weight (dead weight, including that of pump, etc.).
When the slurry pump is started, a mixture of fluidized sand and seawater flows into the suction pipe through the holes in the pipe.

The sand-seawater slurry flows through the suction pipe, is sucked into the slurry pump, and is then transported from the pump through the sand discharge pipe to the sand placement site, where it is discharged.

The slurry is discharged into the sand placement site. There is enclosed by the bank on the landward side.

The slurry infiltrates into the layer of sand at the bottom of the bank, and filters through the existing sand.

The filtered seawater slowly springs up and runs down into the sea.

The remaining sand piles up as part of the bank.

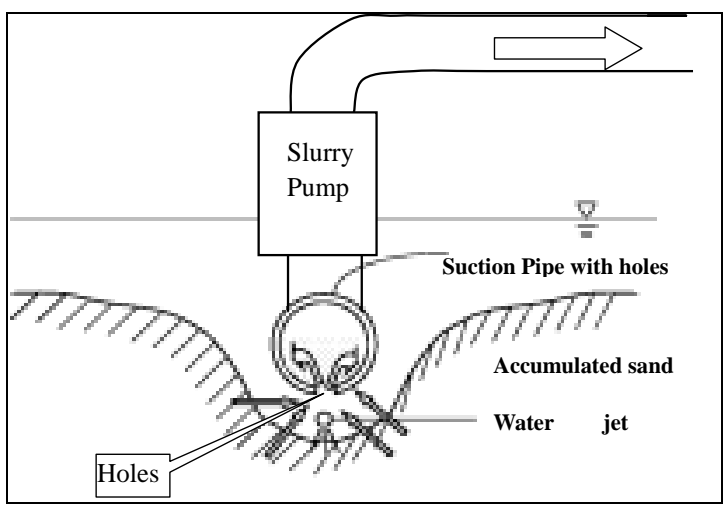

Fig-5 Method (A-A sectional view)

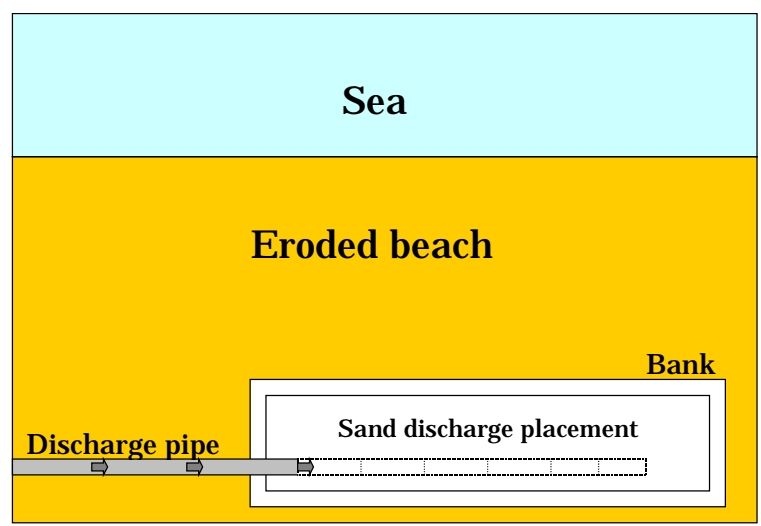

Fig-6 Sand discharge placement plan

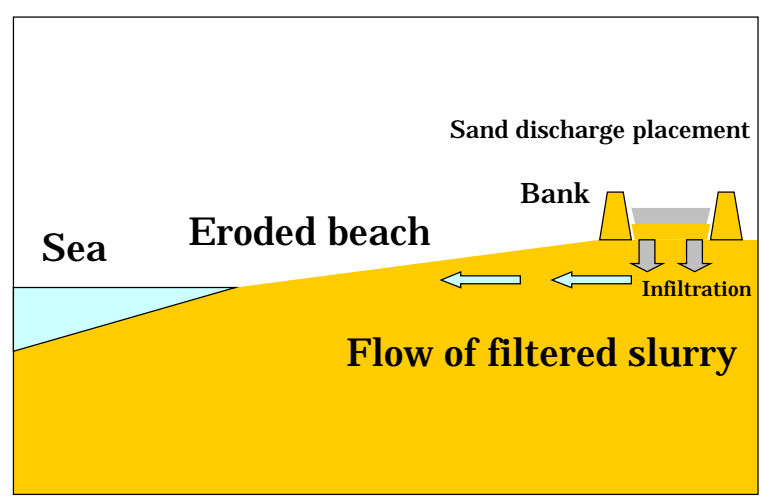

Fig-7 Sand discharge cross section 


\section{LABOR SAVING AND AUTOMATION OF OPERATION AND MANAGEMENT}

To set up the necessary materials and prepare the system requires use of manpower and heavy equipment such as cranes.However, when in operation, the proposed system has benefits of labor saving and automation.

When this method is operated at a seabed acted on by waves, the only operating devices are the slurry pump and the water jet pump.

The only operational requirement of the slurry pump is using an on/off switch when work begins and ends; it is assumed that no further operation or adjustments are required during use.

The operation and management requirements of this method are essentially only the adjustments of the solid concentration rate. It is measured by a slurry density meter mounted on the discharge pipe.

This is assumed to be performed solely by output adjustment of the water jet pump; only one worker is required to do this.

In addition, if the output of the water jet pump is automatically adjusted according to the change in the solid concentration rate, automated operation may be technically possible (Fig.8).

When this method is operated in locations where waves are not acting, it is assumed that the sand collection device can be pulled horizontally with an auto tension winch; the worker becomes unnecessary with an auto tension winch in use.

When the sand collection device moves a significant distance, and the device needs to be relocated, some manual work is required.

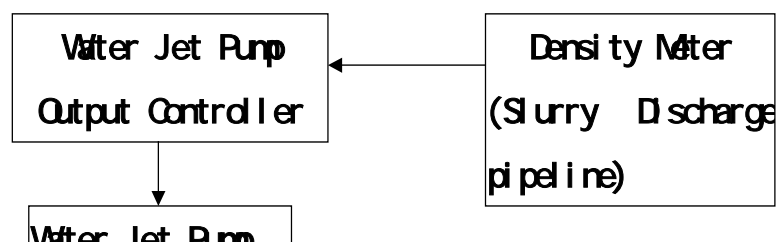

Water Jet Pump

Fig-8 Automated Operation Flow

\section{EXPECTED EFFECTS AND FEATURES}

The main features of the new system may be summarized as follows;

Saves labor and is automated while operating.

Demonstrates continuous sand collection effect.

In principle, does not require a individual mechanism for movement of the sand-collecting device.

Basic power requirements are limited to pump power for sand slurry suction/discharge and jet water feed, and winch if necessary.

\section{SPECIFICATIONS OF EXPERIMENTAL DEVICE}

\subsection{Assumptions}

The outline and basic operating conditions assumed in field experiments to verify the possibility of stable, continuous sand collection using the newly-developed system were as follows.

(1)Assumption sand bypass ability: $21 \mathrm{~m} 3 / \mathrm{h}$

- Sand bypass amount: 40,000 m³/y (approx.).

This value is equivalent to annual bypassing of a sand layer $1 \mathrm{~m}$ thick to a beach $100 \mathrm{~m}$ wide x $400 \mathrm{~m}$ long. - Annual bypassing period: 3 months (approx.)

This period assumes that sand bypassing is performed during the 3-month period before the beach is opened to swimming, considering use in the ocean swimming season. Then, when the operation of 22 hours a day is assumed for 3 months, the sand bypass ability needs $21 \mathrm{~m} 3 / \mathrm{h}$.

(2) Solid concentration (sand content of slurry):15\%

From the equipment viewpoint, a high solid concentration is advantageous because small-diameter pipe can be used in the pipeline. However, considering the pipeline transportation, a high solid concentration also incurs a risk of sand sedimentation, with possible pipeline blockage. Therefore, the solid concentration was assumed to be $10-20 \%$ (apparent volumetric concentration).

(3) Sand grain size: Fine sand

The conditions of the experiment were set up based on the assumptions described above.

\subsection{Experimental Device}

The slurry pump was installed in the center part of suction pipe. The water jet outlets ware arranged under suction pipe.

The water supply pump supplied water to the jet outlet through the hose.

(1) Suction Pipe

-Pipe diameter

A trial calculation was made to determine the required pipe diameter assuming a value of $15 \%$ as the solid concentration and $21 \mathrm{~m} 3 / \mathrm{h}$ as the sand bypass ability:

Trial calculations were made for several pipe inner diameters. As the result of calculation, $150 \mathrm{~mm}$ was selected as the optimum pipe diameter

-Pipe length

From the viewpoint of sand collection effectiveness, a long suction pipe has the advantage of enabling sand collection over a wider area. However, as the pipe length increases, differences in suction pressure tend to occur in the longitudinal direction, preventing smooth sinking of the pipe as a whole.

Considering this, as well as ease of handling in installation and movement, the length was set at $4 \mathrm{~m}$. -Pipe holes

To avoid clogging by trash, stones, etc., the diameter of the suction pipe holes was set on the large side, at $5 \mathrm{~cm}$.

The holes were arranged on the bottom of the pipe (6 o'clock position). Preliminary experiments were conducted with various holes positions in several water-tank experiments and field experiments.

However, when the holes were arranged on top of the pipe, the sand cover on the holes decreased as the sand 
around the pipe was collected until sand could no longer be recovered. In this case, only water was sucked into the pipe, and the slurry concentration decreased.

To avoid this phenomenon, the holes were placed on the pipe bottom.

(2) Slurry pump

The slurry pump is mounted on the suction pipe and is used to collect sand, together with seawater, in the form of slurry and transfer it to the sand discharge pipe. The motor output is $9.0 \mathrm{~kW}$ in seabed experiment and $11 \mathrm{kw}$ in beach experiment.

(3) Water jet

A water jet function for self-sinking is provided to accelerate sand collection through the suction pipe holes and pipe sinking during sand collection by fluidizing the sand.

The feed water pipe consists of a steel pipe with an inner diameter of $100 \mathrm{~mm}$. Jet holes are arranged on the underside of the suction pipe. The feed water pipe is attached on the suction pipe and is supplied with seawater by a pump with a motor output of $9.2 \mathrm{kw}$

(4) Extension of sand discharge pipe line

Extension of sand discharge pipe line is $50 \mathrm{~m}$ in seabed experiment and $70 \mathrm{~m}$ in beach experiment.

In actual sand bypassing, it is much longer. In these experiments, the distance was limited to several tens of meters considering the fact that pump transportation of slurry is an established technique, which is generally used in conventional dredging work and does not involve any particularly large technical problems.

For longer distances, it is necessary to increase the pump capacity. However, if the pump capacity of one unit is insufficient, booster pumps can be provided as required.

(5) Total weight of device

Total weight of device is 0.4 tons (approx.)

6) Measurement equipment

An ultrasonic flow meter and a slurry density meter ware mounted on the discharge pipe.

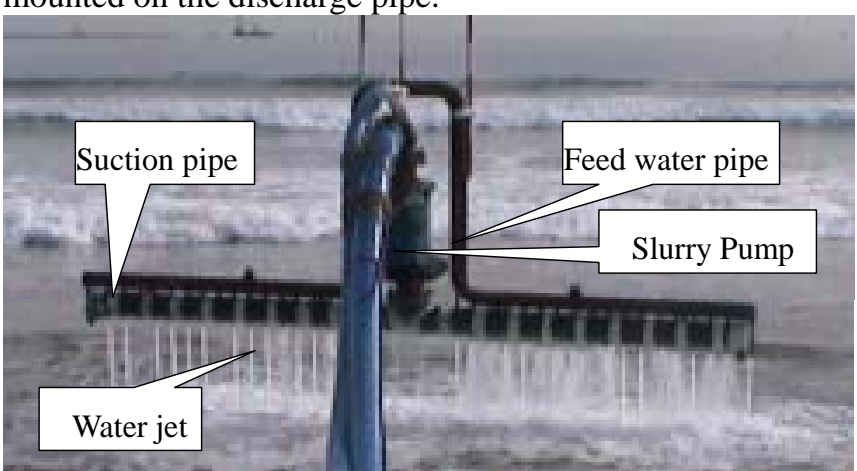

Photo-1 Experimental Sand Collection Device

\subsection{Experimental Condition}

Two cases of sand collection location were assumed, i.e. collection of seabed sand from an underwater marine site and collection of beach sand on land.

In seabed sand collection, wave forces can be expected to cause sand accumulation, supporting sand collection.
However, this cannot be expected with beach sand. These experiments assumed a case where operation is limited to collection/ transportation of sand from land due to the sand quality or other site conditions.

The sand grain size of the both area was fine sand. The particle size showed a mean diameter, D50, of $0.2 \mathrm{~mm}$.

The sand size composition consisted of sand $(75 \mu$ $\mathrm{m}-2 \mathrm{~mm}) 93 \%$, small stone $(2-75 \mathrm{~mm}) 6 \%$, silt $(5-75 \mu \mathrm{m}) 1 \%$.

\section{SEABED SAND COLLECTION EXPERIMENT}

A seabed sand collection experiment was conducted to determine the possibility of continuous collection/transportation of sand accumulating on the seabed in a marine area acted on by waves using the experimental device described above.

The sand collection device was lowered onto the accumulated sand on the seabed by a crane. The water jet pump was started, and the device sank into the sand layer as the accumulated sea bottom sand was excavated by the water jets. (Fig-9)

At the same time, the accumulated sand was fluidized. All of the water jets were directed downward.

The slurry pump was started, drawing fluidized sand into the suction pipe. The sand was transported through the discharge pipe and discharged from the discharge point.

In the seabed sand collection experiment, wave action caused the fluidized sand to flow into the trench that formed around the experimental sand collection device, creating a sand trap. The device gradually sank downward under its own weight (dead weight) as it collected this inflowing sand and the seabed sand.

The crane cable was relaxed during the experiment so that no hoisting load was applied.

At first, the experiment sand collection device sank about approximately $1 \mathrm{~m}$, and then stopped sinking.

The volume of flowing sand into the sand trap must become equal to that of collected sand by the device.

As a result of the experiment, the maximum sand collection volume for continuous one hour was $47 \mathrm{~m} 3 / \mathrm{h}$, and that for half a day was $28 \mathrm{~m} 3 / \mathrm{h}$.

The maximum solid concentration of the slurry was over $50 \%$, but no blockage occurred in the pipe in the experiment, this was attributed to the short pipeline transportation distance of approximately $50 \mathrm{~m}$.

However, conditions can be expected to exceed the pump capacity limit if a high solid concentration continues for an extended time, and pipe blockage is likely.

Therefore, management/control of the solid concentration is an important issue for future study.

Because the action of the water jets greatly influences the solid concentration, it appears that adjustment of the water jets can be effectively utilized in management/control of the solid concentration. 


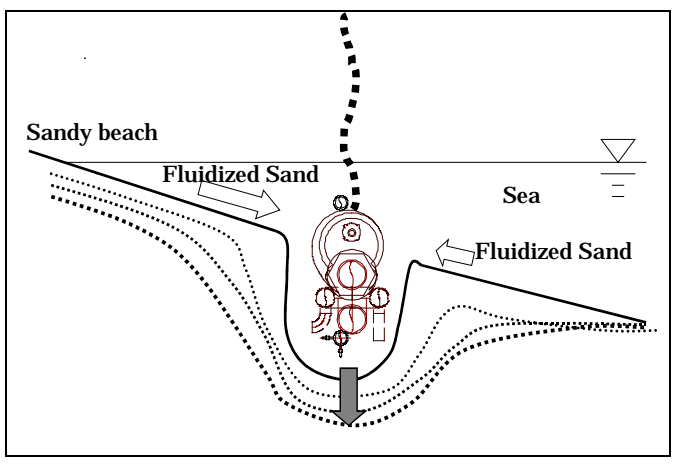

Fig-9 Sectional view of seabed sand collection experiment

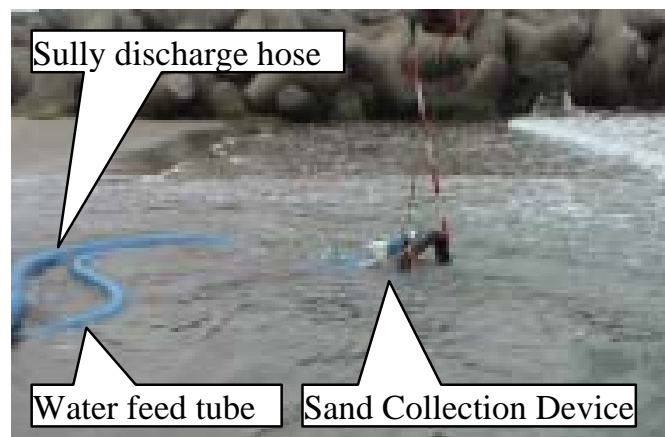

Photo-2 View of seabed sand collection experiment

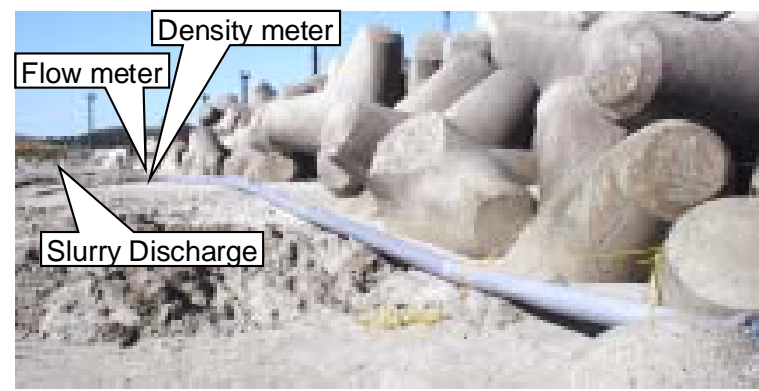

Photo-3 Slurry Discharge Pipeline

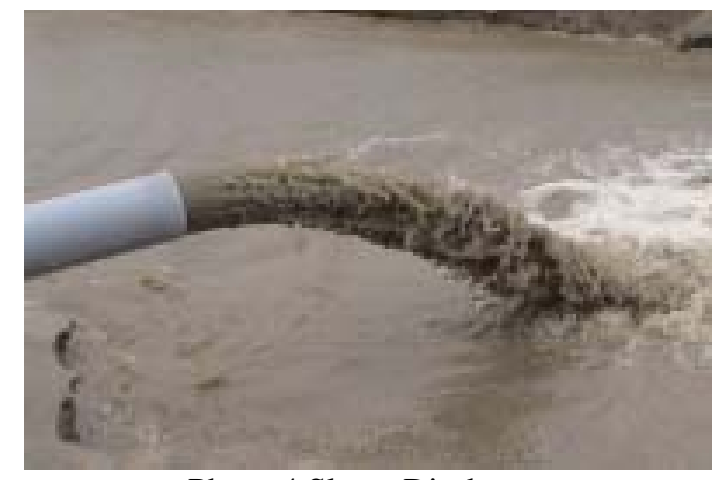

Photo-4 Slurry Discharge

\section{BEACH SAND COLLECTION EXPERIMENT}

Assuming conditions under which no wave action affects the sand collecting process and conditions in which sand must be collected from a dry beach due to various restrictions, an experiment was conducted to determine the possibility of continuous sand collection/ transportation with this device under such circumstances.

A trench for placement of the sand collection device was dug with an excavator at a beach near the sea (approximately 500m from the waterline). The trench was excavated to a depth below sea level, at which seawater began flowing into the trench.

The sand collection device was then lowered into the trench.

The water jet pump was started, and the device was lowered to the bottom of the prepared trench.

In this case, the water jets were alternately directed downward and horizontally. The water jets were started, followed by the slurry pump, which was started after the device was fully lowered into the trench. Excavation of the accumulated sand by the jets allowed the device to sink into the sand layer, while also fluidizing the sand. The fluidized sand was sucked into the suction pipe, transported as slurry, and discharged from the discharge point.

After the sand collection device sank about $1 \mathrm{~m}$, it was slowly pulled roughly horizontally in the electric chain block by constant power of about $0.4 \mathrm{t}$ equal with its own weight.

Thus, beach sand was continuously collected and transported using this device.

As a result of the experiment, the sand collection volume for continuous one hour was $27 \mathrm{~m} 3 / \mathrm{h}$.

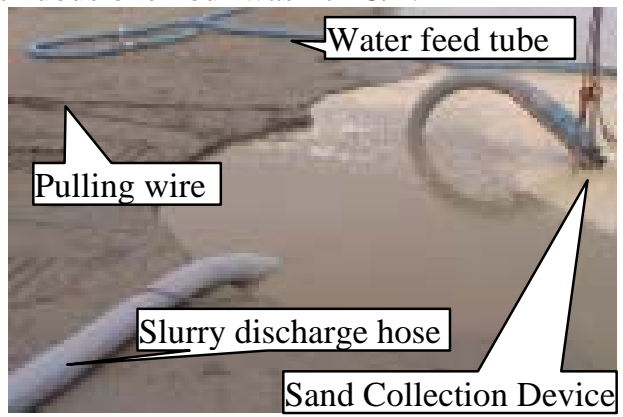

Photo-5 View of beach sand collection experiment

\section{CONSIDERATIONS}

\subsection{Performance}

A graph that compares the sand collection rates of the seabed experiment and the beach sand experiment with an assumed actual construction value of $21 \mathrm{~m} 3 / \mathrm{h}$ (assumed solid content of $15 \%$ and flow quantity $2.3 \mathrm{~m} 3 / \mathrm{min}$ of the slurry) is shown in Figure-10.

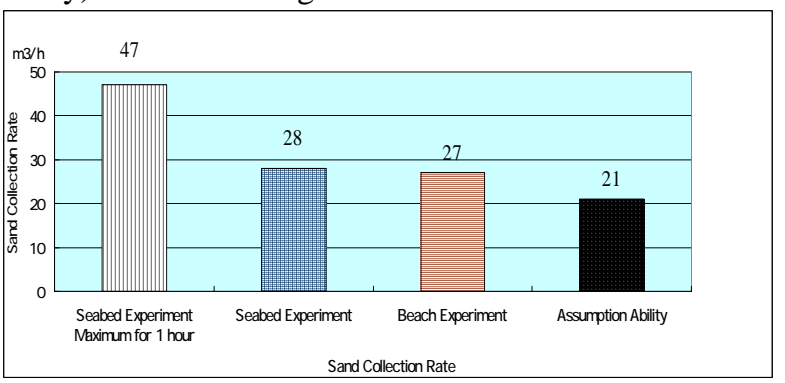

Figure-10 Comparison between experimental values and assumed value of sand collection rates 
The solid concentration rate is assumed to be a low value of $15 \%$; this value is chosen to avoid having to consider generation of pipe blockage over a long distance of transportation.

However, to understand actual performance and the ability that sand was able to be collected continuously, the seabed and beach sand experiments were performed at a higher solid content rate than the assumed actual construction density.

In the experiments the slurry was transported without causing blockage in the pipe as the transportation distance was short, at approximately $50 \mathrm{~m}$.

There is considered to be a technical similarity between the proposed method and the existing slurry transportation by pump dredging method for long distance transportation; in both methods there are no significant technical problems.

Moreover, the volume of sand transported is predominantly determined by the diameter of the pipe used to collect and transport the slurry.

The field experiments performed to date have used a pipe of $150 \mathrm{~mm}$ diameter, and the rate of collection and transportation of sand assumed as the actual construction value is $21 \mathrm{~m} 3 / \mathrm{h}$.

\subsection{Cost}

A cost comparison was performed between the proposed method, "Backhoe loading and dump truck transportation on land", and "Pump dredging and pipe transportation at sea".

Alternative cases with different transportation distances were calculated as part of the comparison.

For the proposed method, costs were calculated for two cases: one where a crane was not used in collection of sand from the seabed in shallow waters where there was wave action, and one for collection of beach sand where a crane was used. The cost calculation results are shown in Fig-11.

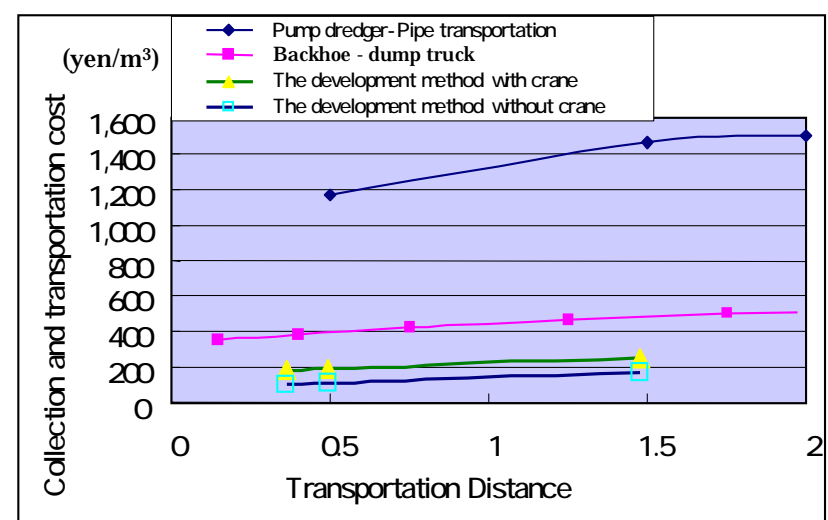

Fig-11 Cost comparison between the proposal method and the conventional method

The cost of the proposed method was approximately half that of the "Backhoe loading and dump truck transportation on land" method.
Moreover, the cost of the proposed method was $1 / 5$ to $1 / 6$ the cost of the "Pump dredging and pipe transportation at sea" method.

8.3 Automation and labor saving of operation management A comparison was performed between the proposed method, "Backhoe loading and dump truck transportation on land", and "Pump dredging and pipe transportation at sea" from the viewpoint of automation and labor saving.

The number of workers necessary in each method is compared.

In the proposed method, if the solid concentration rate can be controlled, fully automated operation can be expected.

For "Backhoe loading and dump truck transportation on land", at least two drivers of two dump trucks and a backhoe operator are needed.

Additionally, a traffic-control worker who guides the dump truck is required as an indirect worker.

For "Pump dredging and pipe transportation at sea", even if a small micro-pump dredger is used, the standard necessary crew is eight people.

\section{CONCLUSION}

A self-sinking sand bypass system that uses a suction pipe with holes to collect sand and water jets to fluidize the surrounding sand and to encourage sinking was proposed.

The effectiveness of the system was demonstrated in field experiments in seabed sand collection and beach sand collection.

1) In the proposed method, if the solid concentration rate can be controlled, fully automated operation can be expected.

2) In the seabed experiment, where sand collection was affected by wave action, continuous collection and transportation of sand for half a day was possible at the same place.

3) In the beach experiment, where sand collection was not supported by wave action, continuous collection and transportation was possible, requiring only horizontal pulling of the sand collection device by constant power of equal with its own weight.

In research for practical application of this system, it will be necessary to demonstrate the continuous effectiveness of the system and investigate problems such as equipment durability in continuous long-term experiments.

For improved efficiency and laborsaving, a simple method of controlling and managing the solid concentration of the slurry to a specified value is also required.

\section{REFERENCES}

1) H.Noguchi, Y.Fujita, I.Fujita, I.Noda, Development of Simple Sand Bypass System Using a Self-Sinking Suction Pipe with Holes, Proceedings of OCEANS'04/ TECHNO-OCEAN'04, pp.1-7, Nov.2004 